\title{
Staphylococcus aureus is the most common bacterial agent of the skin flora of patients with seborrheic dermatitis
}

\author{
Funda Tamer ${ }^{1}$, Mehmet Eren Yuksel $^{2}$, Evren Sarifakioglu ${ }^{3}$, Yavuz Karabag ${ }^{4}$
}

\begin{abstract}
1 Department of Dermatology, Ufuk University School of Medicine, Ankara, Turkey
2 Department of General Surgery, Aksaray University School of Medicine, Aksaray, Turkey

3 Department of Dermatology, Evren Sarifakioglu Clinic, Ankara Turkey

4 Department of Cardiology, Kafkas University School of Medicine, Kars, Turkey
\end{abstract}

Key words: bacterial skin flora, Malassezia, seborrheic dermatitis, Staphylococcus aureus

Citation: Tamer F, Yuksel ME, Sarifakioglu E, Karabag Y. Staphylococcus aureus is the most common bacterial agent of the skin flora of patients with seborrheic dermatitis. Dermatol Pract Concept. 2018;8(2):80-84. DOI: https://doi.org/10.5826/dpc.0802a04

Received: September 25, 2017; Accepted: January 8, 2018; Published: April 30, 2018

Copyright: $@ 2018$ Tamer et al. This is an open-access article distributed under the terms of the Creative Commons Attribution License, which permits unrestricted use, distribution, and reproduction in any medium, provided the original author and source are credited.

Funding: None.

Competing interests: The authors have no conflicts of interest to disclose.

All authors have contributed significantly to this publication.

Corresponding author: Funda Tamer, MD, Assistant Professor, Department of Dermatology, Ufuk University School of Medicine, Mevlana Bulvari (Konya Yolu), No 86-88, 06510, Balgat, Ankara, Turkey Tel: +903122044151. Email: fundatmr@yahoo.com

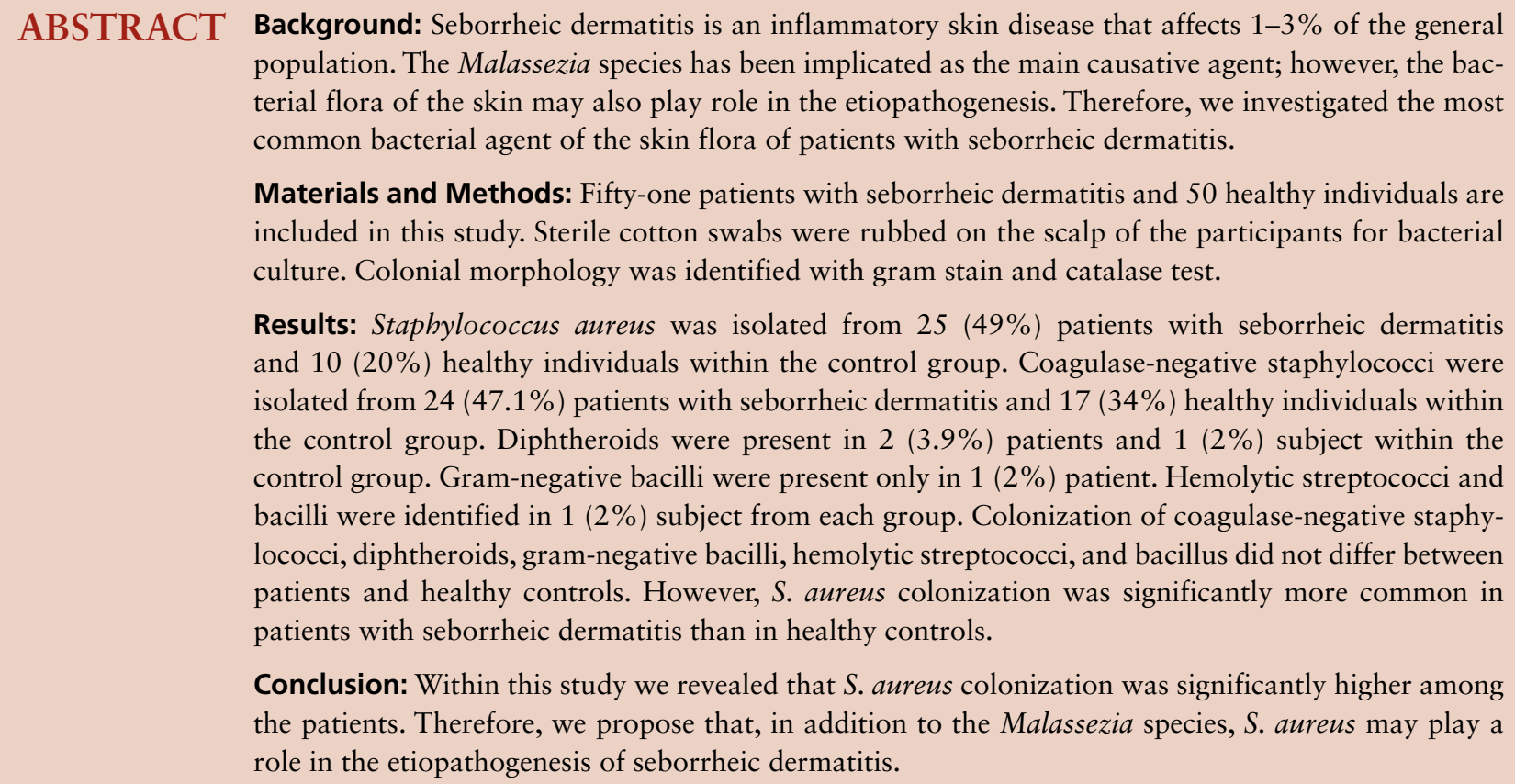




\section{Introduction}

Seborrheic dermatitis is a chronic inflammatory skin disease that affects $1-3 \%$ of the general population [1]. Seborrheic dermatitis is more common in men than in women and usually occurs in adolescents and young adults. Seborrheic dermatitis presents with erythematous, yellowish, greasy, scaly plaques. The lesions predominantly occur on sebaceous gland-rich areas like scalp, eyebrows, ears, nasolabial folds, chest, axillae, and groin [1]. The diagnosis of seborrheic dermatitis is usually made on the basis of its clinical features. The etiology remains unknown; however, Malassezia yeasts, skin sebum levels, androgens, and immunologic mechanisms have been described as contributing factors [2]. Overgrowth of Malassezia species has been found to be associated with inflammation in seborrheic dermatitis. However, similar amounts of Malassezia species have also been reported in patients with seborrheic dermatitis and control groups [2,3]. Nevertheless, bacterial skin microbiota has been implicated in the pathogenic process of seborrheic dermatitis [4]. Propionibacterium acnes and micrococci like Micrococcus butyricus, Micrococcus pyogenes var. aureus have been considered as possible etiologic agents [5]. However, the association of bacteria with seborrheic dermatitis remains controversial [4]. Therefore, in this study, we aim to investigate the most common bacterial agent of the skin flora in patients with seborrheic dermatitis.

\section{Materials and Methods}

This study included 51 patients with seborrheic dermatitis of the scalp and 50 healthy individuals within the control group who were admitted to the dermatology outpatient clinic between February and April 2016. All participants provided written informed consent. The exclusion criteria were having an inflammatory skin disease like psoriasis or lichen planus and receiving any topical or systemic treatment for seborrheic dermatitis. The scoring index that was described by Koca et al was used to determine the severity of seborrheic dermatitis [6]. We evaluated the presence of erythema, desquamation, pruritus and irritation as absent (0), mild (1), moderate (2) and severe (3) according to Koca scoring index. The sum of these values indicated the severity of seborrheic dermatitis (0-4; mild, 5-8; moderate, 9-12; severe).

Sterile cotton swabs were moistened with sterile distilled water and rubbed on the frontal aspect of the scalp of each participant for bacterial culture. The test site was uniform for all the patients and the control group. The samples were taken from skin lesions of the patients with seborrheic dermatitis and normal skin of the healthy individuals within the control group. The samples were plated on $5 \%$ sheep blood agar and chocolate agar. Afterward, they were incubated at $37^{\circ} \mathrm{C}$ for 48 hours under aerophilic and capnophilic conditions. The microorganisms were identified by conventional methods. Colonial morphology was identified with gram stain and catalase test. Catalase positive, coagulase positive, and gram-positive cocci that produced yellow pigmentation on mannitol-salt agar were described as $S$. aureus.

Statistical analysis was performed using SPSS 22.0 (SPSS Inc., Chicago, IL). Continuous variables were defined as the mean $( \pm)$ standard deviation and medians (minimum-maximum). Categorical variables were expressed as percentages. Differences between groups were analyzed by Independent Samples $t$ test for numerical variables and chi-square test for categorical variables. A p-value $<0.05$ was considered statistically significant.

\section{Results}

Fifty-one patients with seborrheic dermatitis (28 female, 23 male) and 50 healthy individuals within the control group (30 female, 20 male) were included in the study ( $\mathrm{p}=0.60)$. The median age of the patients and control group was 27 years (range: 17 to 57 years, $95 \%$ confidence interval [CI]: 24-32) and 28 years (range: 17 to 56 years, 95\% CI: 26-35), respectively $(\mathrm{p}=0.35)$. Seven $(13.7 \%)$ patients with seborrheic dermatitis had a family history of seborrheic dermatitis. The median disease duration was four years (range: 1-40 years, 95\% CI: 3-10) (Table 1). In addition to scalp involvement, $8(15.7 \%)$ patients had seborrheic dermatitis lesions on the eyebrows, $6(11.8 \%)$ patients had lesions on nasolabial folds, $5(9.8 \%)$ patients had lesions on the retroauricular region, 3 $(5.9 \%)$ patients had lesions on the chest and $1(2 \%)$ patient had lesions on the glabella. According to the Koca scoring index, $24(47.1 \%)$ patients had mild seborrheic dermatitis, $22(43.1 \%)$ patients had moderate seborrheic dermatitis, and $5(9.8 \%)$ patients had severe seborrheic dermatitis. Table 2 shows the results of bacterial cultures. S. aureus was isolated from 25 (49\%) patients with seborrheic dermatitis and $10(20 \%)$ healthy individuals within the control group. Coagulase-negative staphylococci were isolated from 24 (47.1\%) patients with seborrheic dermatitis and 17 (34\%) healthy individuals within the control group. Diphtheroids were present in $2(3.9 \%)$ patients, and $1(2 \%)$ subject within the control group Gram-negative bacilli were present only in $1(2 \%)$ patient. Hemolytic streptococci and Bacillus were identified in $1(2 \%)$ subject from each group. Colonization of coagulase-negative staphylococci, diphtheroids, gram-negative bacilli, hemolytic streptococci and bacillus did not differ significantly between patients and healthy controls $(\mathrm{p}=0.18$, 0.57, 0.32, 0.99 and 0.99, respectively). However, S. aureus was significantly more frequent in patients with seborrheic dermatitis compared to the control group $(\mathrm{p}=0.02)$. 
TABLE 1. Demographic features of the subjects and disease severity score in patients with seborrheic dermatitis

\begin{tabular}{|c|c|c|c|}
\hline & $\begin{array}{l}\text { Patients with } \\
\text { Seborrheic Dermatitis } \\
\qquad(\mathrm{n}=\mathbf{5 1})\end{array}$ & $\begin{array}{l}\text { Healthy Controls } \\
\qquad(n=50)\end{array}$ & P-value \\
\hline \multicolumn{4}{|l|}{ Age (years) } \\
\hline Mean \pm sd & $30.6 \pm 11.4$ & $32.7 \pm 10.7$ & 0.35 \\
\hline Median/range & $27 /(17-57)$ & $28 /(17-56)$ & \\
\hline $95 \% \mathrm{CI}$ & $24-32$ & $26-35$ & \\
\hline \multicolumn{4}{|l|}{ Gender (n/\%) } \\
\hline Female & $28(54.9 \%)$ & $30(60 \%)$ & 0.60 \\
\hline Male & $23(45.1 \%)$ & $20(40 \%)$ & 0.60 \\
\hline \multicolumn{4}{|c|}{ Disease duration (years) } \\
\hline Mean \pm sd & $7.30 \pm 8.50$ & & \\
\hline Median/range & $4 /(1-40)$ & & \\
\hline $95 \% \mathrm{CI}$ & $3-10$ & & \\
\hline \multicolumn{4}{|c|}{ Disease severity (n/\%) } \\
\hline Mild & $24(47.1 \%)$ & & \\
\hline Moderate & $22(43.1 \%)$ & & \\
\hline Severe & $5(9.8 \%)$ & & \\
\hline
\end{tabular}

sd: standard deviation

CI: Confidence interval

The patients and healthy individuals in the control group were statistically similar in age and gender; 46 patients (90.2\%) had mild to moderate seborrheic dermatitis. Only 5 patients $(9.8 \%)$ had severe seborrheic dermatitis according to the seborrheic dermatitis disease severity scoring index that was described by Koca et al.

TABLE 2. Bacterial culture results of the patients with seborrheic dermatitis and control group

\begin{tabular}{|l|c|c|c|}
\multicolumn{1}{|c|}{ Isolated Bacteria } & $\begin{array}{c}\text { Patients With Seborrheic } \\
\text { Dermatitis } \\
(\mathbf{n} / \%)\end{array}$ & $\begin{array}{c}\text { Healthy Controls } \\
\mathbf{( n / \% )}\end{array}$ & P value \\
\hline Staphylococcus aureus & $25(49.0 \%)$ & $10(20.0 \%)$ & 0.02 \\
\hline Coagulase-negative staphylococci & $24(47.1 \%)$ & $17(34.0 \%)$ & 0.18 \\
\hline Diphtheroids & $2(3.9 \%)$ & $1(2.0 \%)$ & 0.57 \\
\hline Gram-negative bacilli & $1(2.0 \%)$ & $0(0.0 \%)$ & 0.32 \\
\hline Hemolytic streptococci & $1(2.0 \%)$ & $1(2.0 \%)$ & 0.99 \\
\hline Bacillus & $1(2.0 \%)$ & $1(2.0 \%)$ & 0.99 \\
\hline
\end{tabular}

S. aureus colonization was significantly more common in patients with seborrheic dermatitis than in healthy individuals $(\mathrm{p}=0.02)$. Colonization of coagulase-negative staphylococci, Diphtheroids, gram-negative bacilli, hemolytic streptococci and Bacillus were statistically similar in patients and healthy controls.

\section{Discussion}

The etiopathogenesis of seborrheic dermatitis is not clearly understood. However, Malassezia species has been implicated as the main causative agent in seborrheic dermatitis [7]. In addition, Karincaoglu et al indicated that Demodex folliculorum might play a role in the etiopathogenesis of seborrheic dermatitis. Karincaoglu et al claimed that the Demodex mite was significantly more prevalent in patients with seborrheic dermatitis compared to healthy controls [8]. Nevertheless, Tehrani et al showed no association between seborrheic dermatitis and demodicosis. Tehrani et al investigated the prevalence of seborrheic dermatitis in patients with Demodex infestation. Included in their study were 123 demodicosis positive patients and 57 demodicosis negative individuals. The prevalence of seborrheic dermatitis in patients with 
demodicosis was $63.4 \%$ and in Demodex negative subjects was $57.9 \%$. The results did not show statistically significant differences between the two groups [9].

There have been a few studies investigating the bacterial flora of the patients with seborrheic dermatitis. In 1954, Pachtman et al reported no correlation between bacteriologic flora and seborrheic dermatitis. The most frequent bacteria isolated from both seborrheic and normal subjects were micrococci and some Corynebacterium species [5]. In 1975, McGinley et al evaluated scalp flora of the patients with dandruff, patients with seborrheic dermatitis, and healthy controls. Coagulase-negative cocci were the most common bacteria isolated from all subjects. However, S. aureus was identified in $20 \%$ of the patients with seborrheic dermatitis, while it was uncommon in patients with dandruff and healthy controls [10]. In 1978, Ihrke et al investigated bacterial flora of normal and seborrheic canine skin. Cutaneous flora of seborrheic dogs consisted mostly of $S$. aureus, while the flora of normal dogs consisted primarily of coagulase-negative cocci [11]. In 1980, Höffler et al investigated the bacterial flora of non-affected skin of patients with seborrheic dermatitis and bacterial skin flora of healthy individuals. Höffler et al reported that the mean count for Propionibacteria in the pilosebaceous ducts of the forehead was reduced in patients compared to the control group. In addition, the mean counts of the coagulase-negative staphylococci were the same on the backs of the patients and healthy individuals [12]. In 2016, Tanaka et al examined bacterial microbiota of lesional and non-lesional skin of patients with seborrheic dermatitis. Acinetobacter, Corynebacterium, Staphylococcus, Streptococcus, and Propionibacterium were found on both lesional and non-lesional sites. However, Propionibacterium was predominantly present on non-lesional skin. Acinetobacter, Staphylococcus and Streptococcus were predominantly present on lesional sites. Tanaka et al suggested that bacterial microbiota might play a role in the development of seborrheic dermatitis by hydrolyzing sebum and providing nutrients for Malassezia [13]. Park et al investigated scalp microbiome in patients with dandruff, seborrheic dermatitis and healthy individuals. Bacteroides, Propionibacterium and Chryseobacterium revealed by random forest analysis showed an increase in disease groups. Park et al claimed that symptoms such as itching, burning, and pain were caused by bacterial community [14].

In our study, $S$. aureus and coagulase-negative staphylococcus were the most common bacteria isolated from the patient and control groups, respectively. S. aureus colonization was significantly more frequent in the skin lesions of patients with seborrheic dermatitis $(49 \%)$ than in healthy subjects within the control group $(20 \%)$. There was no clinical sign and symptom of any bacterial infection in the lesions of the patients with seborrheic dermatitis. In addition, coagulase-negative Staphylococcus was more com- mon in patients $(47.1 \%)$ than in healthy subjects $(34.0 \%)$. However, colonization of coagulase-negative staphylococci, diphtheroids, gram-negative bacilli, hemolytic streptococci and bacillus did not show statistically significant difference between the patient and control group.

We have revealed that bacterial skin communities of the patients with seborrheic dermatitis are different from the healthy individuals. S. aureus was significantly more common among the patients. Our results are consistent with the previous studies reported by McGinley et al in 1975 and by Ihrke et al in 1978. McGinley et al isolated S. aureus from $21 \%$ of seborrheic dermatitis cases, $4 \%$ of normal subjects and $3 \%$ of patients with dandruff. Ihrke et al demonstrated that skin flora of dogs with seborrheic dermatitis were mainly composed of $S$. aureus. However, humans and canines are different species, making a direct comparison is not possible.

In conclusion, bacterial diversity in the skin lesions of seborrheic dermatitis as interactions between Malassezia species and bacterial flora of the skin seem to be associated with the development of seborrheic dermatitis. S. aureus is a pathogenic microorganism commonly found in the skin flora of the patients with seborrheic dermatitis. We propose that, in addition to Malassezia species, $S$. aureus may play a role. Therefore, appropriate antibiotic therapy should be considered in the treatment of severe and persistent seborrheic dermatitis cases.

\section{References}

1. Clark GW, Pope SM, Jaboori KA. Diagnosis and treatment of seborrheic dermatitis. Am Fam Physician. 2015;91:185-190.

2. Gupta AK, Bluhm R. Seborrheic dermatitis. J Eur Acad Dermatol Venereol. 2004;18:13-26.

3. Dessinioti C, Katsambas A. Seborrheic dermatitis: etiology, risk factors, and treatments: facts and controversies. Clin Dermatol. 2013;31:343-351.

4. Paulino LC. New perspectives on dandruff and seborrheic dermatitis: lessons we learned from bacterial and fungal skin microbiota. Eur J Dermatol. 2017;27:4-7.

5. Pachtman EA, Vicher EE, Brunner MJ. The bacteriologic flora in seborrheic dermatitis. J Invest Dermatol. 1954;22:389-396.

6. Koca R, Altinyazar HC, Esturk E. Is topical metronidazole effective in seborrheic dermatitis? A double-blind study. Int J Dermatol. 2003;42:632-635.

7. Sampaio AL, Mameri AC, Vargas TJ, Ramos-e-Silva M, Nunes AP, Carneiro SC. Seborrheic dermatitis. An Bras Dermatol. 2011;86:1061-1071.

8. Karincaoglu Y, Tepe B, Kalayci B, Atambay M, Seyhan M. Is Demodex folliculorum an aetiological factor in seborrhoeic dermatitis? Clin Exp Dermatol. 2009;34:516-520.

9. Tehrani S, Tizmaghz A, Shabestanipour G. The Demodex mites and their relation with seborrheic and atopic dermatitis. Asian Pac J Trop Med. 2014;7S1:S82-84.

10. McGinley KJ, Leyden JJ, Marples RR, Kligman AM. Quantitative microbiology of the scalp in non-dandruff, dandruff, and seborrheic dermatitis. J Invest Dermatol. 1975;64:401-405. 
11. Ihrke PJ, Schwartzman RM, McGinley K, Horwitz LN, Marples RR. Microbiology of normal and seborrheic canine skin. Am J Vet Res. 1978;39:1487-1489.

12. Höffler U, Gloor M, Peters G, et al. Qualitative and quantitative investigations on the resident bacterial skin flora in healthy persons and in the non-affected skin of patients with seborrheic eczema. Arch Dermatol Res. 1980;268:297-312.
13. Tanaka A, Cho O, Saito C, Saito M, Tsuboi R, Sugita T. Comprehensive pyrosequencing analysis of the bacterial microbiota of the skin of patients with seborrheic dermatitis. Microbiol Immunol. 2016;60:521-526.

14. Park T, Kim HJ, Myeong NR. Collapse of human scalp microbiome network in dandruff and seborrhoeic dermatitis. Exp Dermatol. 2017;26:835-838. 